\title{
O empresariado urbano nos projetos de revitalização portuária no Rio de Janeiro
}

\author{
Urban entrepreneurs in port revitalization projects in Rio de Janeiro
}

Júlia Erminia Riscado [I]

\begin{abstract}
Resumo
0 presente artigo tem como objetivo analisar a atuação do empresariado urbano na zona portuária carioca até a implantação do Projeto Porto Maravilha. De início, o artigo aborda as referências teóricas que norteiam os estudos sobre o lugar dos grupos de interesse no processo de formulação de agendas, ressaltando o papel dos empreendedores políticos. A segunda parte da exposição traz uma recuperação histórica dos projetos de revitalização para a região portuária desde a década de 1980. A partir do recorte estabelecido, foi possível observar a participação de determinados grupos empresariais e agentes públicos envolvidos na elaboração dos projetos. Pretendeu-se identificar, com isso, seu papel relevante na gestão e na elaboração de políticas urbanas na cidade do Rio de Janeiro.
\end{abstract}

Palavras-chave: empresariado; grupos de interesse; zona portuária; revitalização; Rio de Janeiro.

\begin{abstract}
This article aims to analyze the performance of urban entrepreneurs in the Rio de Janeiro port area up to the implementation of the Porto Maravilha Project. Initially, the article addresses the theoretical references that guide studies about the place of interest groups in the process of formulating agendas, highlighting the role of political entrepreneurs. The second part of the article provides a historical recovery of the revitalization projects for the port region since the 1980s. Based on this, it was possible to observe the participation of certain business groups and public agents in the development of the projects. Our intention was to identify their relevant role in the management and in the making of urban policies in the city of Rio de Janeiro.
\end{abstract}

Keywords: business community; interest groups; port area; revitalization; Rio de Janeiro. 


\section{Introdução}

A implantação de indústrias e a mecanização do campo intensificaram de maneira drástica os problemas de ordem social, econômica, política e cultural nas cidades. Além do crescimento demográfico e do desenvolvimento dos núcleos urbanos, as consequências e as destruições produzidas por duas guerras mundiais contribuíram para a emergência dos estudos sobre a questão urbana.

No Brasil, o tema ganhou força durante a elaboração da Constituição de 1988. Nesse momento, buscou-se unir esforços em torno da tentativa de restaurar a Federação e oferecer meios para a participação democrática de seus cidadãos. Com a retomada de pautas e a valorização de novos temas, a questão urbana surgiu como elemento fundamental no processo de democratização do País.

Nessa ocasião, houve uma normatização de medidas que serviram para nortear o exercício do direito de propriedade nas grandes cidades e metrópoles. Além disso, foram conferidas maior autonomia administrativa e capacidade político-financeira aos municípios. 0 estabelecimento das leis orgânicas municipais incorporou novos mecanismos institucionais à organização política e administrativa municipal. Por meio de audiências e consultas públicas, conselhos e fóruns, foram estabelecidos novos canais de participação na elaboração dos planos diretores e das políticas públicas locais.

Contudo, além dos movimentos sociais e das organizações de caráter civil, outras representações utilizaram esses espaços para se mobilizarem e garantirem seus interesses. A presença de setores organizados do turismo e dos mercados imobiliário e financeiro também foi decisiva para a orientação das políticas urbanas locais. Percebe-se, com isso, que o desafio na construção da agenda urbana democrática ultrapassa a divergência de interesses entre Estado e sociedade civil. É necessário também examinar a reorientação na forma de representação política do empresariado, a partir da redemocratização, para compreender seu papel na estrutura atual do Estado brasileiro.

Em 1986, por exemplo, o número de empresários eleitos para a Constituinte ficou entre cerca de $32 \%$ a $45,26 \%$. Desse grupo, pouco mais de $20 \%$ era composto por empresários urbanos, o que mostra ainda a pouca necessidade por parte dos empresários industriais e financeiros em se fazerem representar no Legislativo (Diniz e Boschi, 2000, p. 15).

Porém, a capacidade de adaptação do empresariado urbano pôde ser notada no aumento expressivo de sua atuação política durante o governo de transição de José Sarney. Com a intensificação da mobilização social e da participação política de diferentes grupos da sociedade civil, exigiu-se do Estado maior envolvimento quanto à sustentação e à promoção do desenvolvimento econômico nacional. Foi, a partir desse momento, que se tornou claro o esgotamento do antigo modelo de desenvolvimento e do seu arcabouço institucional que levaram à readaptação da estrutura corporativa e à redefinição das formas de acesso ao Estado.

Após a formulação da Constituição de 1988, o Congresso estava orientado para a aprovação de reformas constitucionais que compunham uma agenda neoliberal, como é o caso da Lei de Modernização dos Portos de 1993. E embora o governo Sarney mantivesse um presidencialismo de caráter centralista, 
aspecto determinante para a condução de reformas e políticas baseadas no modelo tecnocrático de gestão econômica, seria possível identificar certa convergência de interesses entre Executivo e Legislativo.

Aos poucos, a participação empresarial sairia dos conselhos e das comissões consultivas para entrar no Congresso, que se tornou uma importante arena de disputa entre os diferentes grupos de interesse. Desse modo, a vinculação não se daria apenas na esfera corporativa, mas também de modo personalista e clientelista.

A presença desses "empreendedores políticos" (Kingdon, 2003) tornou-se fundamental para a compreensão dos novos rumos governamentais. Embora não se encontrem necessariamente em uma posição formal de autoridade, esses indivíduos costumam ocupar posições estratégicas em suas áreas profissionais e exercer influência na opinião pública (Christopoulos, 2006; Mintrom e Nornan, 2009). Além de defenderem seus interesses específicos com investimento em recursos, capital social e estabelecimento de coalizões políticas, tais atores acabam se consolidando como um subgrupo influente no espaço político e interferindo diretamente nas escolhas coletivas (Zahariadis, 2007).

Com base nesse viés analítico, considera-se a existência de um modelo de interação paralelo ao governamental significativamente presente na dinâmica política que envolve a concepção de agenda. Por levarem características comuns do meio empresarial à gestão pública, como visão estratégica e habilidades específicas na concepção e condução de grupos, tais atores dependem da manutenção das redes de influência para se conservarem dentro daquele contexto. Para manterem sua capacidade de ação política, precisam estimular uma alteração no comportamento dos atores políticos, tornando-os mais afinados aos padrões empresariais.

Nesse sentido, este artigo se propõe a observar como essa rede de relações é importante para entender os projetos de revitalização para a região portuária da cidade do Rio de Janeiro desde a década de 1980. Espera-se, a partir de um exercício de análise empírica e teórica, refletir sobre o papel desses empreendedores políticos na política urbana da cidade.

\section{O empresariado na política nacional}

A aproximação do empresariado brasileiro com a classe política consolidou-se tão logo se iniciou o processo de industrialização no País. Com o tempo, aquele grupo se tornou determinante no desenho dos projetos de desenvolvimento nacional.

A organização dos industriais como classe tem origem no fim do século XIX, predominantemente nos estados de Minas Gerais e Rio de Janeiro, duas importantes localidades para a economia agroexportadora da época. Nesse momento, a indústria têxtil era responsável por $60 \%$ do capital industrial gerado e ainda sofria com os investimentos estatais em infraestrutura ligados à ascensão da economia cafeeira-exportadora.

De acordo com autores como Warren Dean (1971), Maria da Conceição Tavares (1972), José de Souza Martins (1986) e Wilson Cano (1998), a atividade cafeeira foi a responsável por criar as condições necessárias ao desenvolvimento industrial do 
País. A acumulação de capital da cafeicultura gerou excedente que, por iniciativa dos próprios fazendeiros de café, foi investido no desenvolvimento da atividade industrial. Tal iniciativa explicaria a transformação de parte da elite rural em "homens de negócios" (Fernandes, 1987, p. 113).

Os investimentos em questão contribuíram para o surgimento da grande indústria no País. Segundo levantamento realizado pelo Centro Industrial do Brasil de 1907, pelo menos 39 mil operários trabalhavam nas grandes empresas do País. Desse número, 13 mil apenas na cidade do Rio de Janeiro. Com base nos dados apresentados, essa linha interpretativa considerou que o setor nasce tendo como base de sustentação a grande indústria:

As indústrias que surgiram no período já empregavam um grande número de trabalhadores e um capital de grande valor. Caracterizavam-se também pela profunda mecanização e pela consolidação da separação entre trabalhador e meios de produção - pressuposto fundamental do sistema capitalista. A industrialização brasileira não foi, portanto, precedida por nenhuma fase manufatureira. 0 seu início, já com plena mecanização do processo de trabalho, foi também uma exigência do próprio momento em que ela surgiu. (Perissinotto, 1991, p. 218)

Em outros trabalhos, contudo, o surgimento da indústria no País não esteve atrelado ao complexo agroexportador. Para Bresser-Pereira (2002, p. 146), “os empresários industriais do Estado de São Paulo, onde se concentrou a industrialização brasileira, não tiveram origem nas famílias ligadas ao café. Originaram-se em famílias imigrantes principalmente de classe média". Nesse caso, como apontou Silva (1976), não seriam os imigrantes pobres que vieram ao País como trabalhadores braçais, mas aqueles que possuíam recursos e vinham investir no setor industrial emergente.

Outro ponto de divergência entre estudiosos do empresariado industrial brasileiro reside na percepção sobre a capacidade organizativa da categoria. Vianna (1987), Fernandes (1987) e Sodré (1967) apontaram para a incapacidade organizacional da categoria, capaz de minar qualquer atuação política contundente. Em contraposição, lanni (1989), Diniz (1978), Boschi (1979) e Leopoldi (2000) identificaram a atuação do empresariado atrelada a seus interesses de classe.

Para lanni (1989, p. 94), a participação política do empresariado industrial estabelece-se após 1930, quando "as transformações da estrutura econômica abriram possibilidades de ampliação e diversificação da produção industrial". É, nesse contexto, que a burguesia industrial emergente passa a atuar no sentido de promover mudanças no aparelho estatal que beneficiassem a categoria. Consequentemente, acabou contribuindo para um processo de reorientação da político-econômica do Estado.

Essa perspectiva reconheceu o caráter organizado e politicamente ativo na atuação do empresariado industrial brasileiro. Apesar da dependência em relação ao Estado, como destacou Boschi (1979, pp. 53-54), "os empresários puderam estabelecer um estilo de interação entre os setores privado/público, abrindo um espaço à participação direta em questões-chave relacionadas aos seus interesses enquanto classe". Essa especificidade comportamental do empresariado industrial, que não pode ser entendida como submissão, 
contribuiu com e promoveu o estabelecimento de novas formas de interação com os segmentos estatais.

De acordo com Leopoldi (2000), o corporativismo foi o meio encontrado pelos industriais de iniciarem os primeiros contatos e negociações com o Estado. Com o tempo, as entidades da indústria e do comércio demonstraram força suficiente para atuarem de modo autônomo em face dos acontecimentos da política nacional.

Os industriais do eixo Rio-São Paulo conviveram com regimes de tipo oligárquico, liberal e ditatorial. Desde 1930, contudo, conseguiram fazer com que o Estado, a despeito de sua presença crescente na economia, respeitasse a sua liberdade de organização em entidades privadas, paralelas ao sindicalismo oficial.

[...] em nenhum momento recorrendo a um discurso que sugerisse intenções hegemônicas, a liderança da Fiesp e CNI foi pondo em prática uma série de medidas, estabelecendo alianças estratégicas com o governo e com os militares, criando formas de controlar o movimento operário, ações que indicavam claramente sua busca de uma hegemonia política. (Ibid., pp. 86-87)

A postura adotada pelo empresariado nacional foi determinante para que suas pautas fossem inseridas na agenda governamental por meio de influência exercida pelas entidades e confederações ou pela atuação de membros de entidades empresariais em cargos públicos. Durante o governo Dutra, Morvan Dias Figueiredo tornou-se Ministro do Trabalho, Indústria e Comércio, transmitindo os interesses da Fiesp para tratar de questões trabalhistas, por exemplo. Merece destaque, ainda, a presença de dois industriais no $\mathrm{Mi}$ nistério da Fazenda, entre os anos de 1949 e 1953, Guilherme da Silveira e Horácio Lafer. ${ }^{1}$

Pode-se observar que a teoria encontrou dificuldade em compreender o comportamento do empresariado nacional. Em princípio, a literatura voltou-se à composição dos primeiros industriais do País. Posteriormente, o foco analítico esteve na atuação política desse grupo, de modo que seus interesses pudessem ser atendidos ou incorporados na agenda governamental.

Alguns trabalhos reconheceram a ativa participação política da burguesia industrial brasileira durante o processo de industrialização tanto nos regimes democráticos quanto nos autoritários, como nos anos do Estado Novo e na ditadura militar (Diniz e Boschi, 1978; Leopoldi, 1984). Essa flexibilidade comportamental tornou-se característica fundamental para o entendimento da atuação do grande empresariado brasileiro na união em torno da instauração do regime militar e na campanha pela redemocratização, quando rompe com a alta cúpula do Exército que se encontrava no poder desde 1964 para tornar-se um dos grupos mais atuantes na Assembleia Nacional Constituinte (Dreifuss, 1981; Payne, 1994).

Além disso, o setor utilizou-se de diferentes canais de participação, como entidades de classe, alianças momentâneas estabelecidas entre burocratas e administradores de empresas públicas e a ação individual dos empreendedores políticos. Ao explorar novas formas de participação e representação política, o empresariado brasileiro mostrou-se menos propenso a ações coletivas em torno de propostas integradas.

Para alguns autores, essa característica demonstra a incapacidade do setor em influenciar o poder público. No entanto, como 
lembra Mancuso (2007, p. 137), essa tese desconsidera aspectos importantes. Em primeiro lugar, a organização e a mobilização do empresariado sempre existiram ao longo dos anos, sendo mais contundentes na década de 1990.

Ao propor uma política de combate à crise econômica que atingiu o País desde a década anterior, o governo Collor promoveu a abertura da economia brasileira ao comércio internacional. Esse movimento reduziu barreiras tarifárias para as importações e, ao mesmo tempo, auxiliou a inserção do País em novos mercados. Nesse momento, o Brasil envolveu-se em novas negociações internacionais, como o processo de liberalização comercial da Área de Livre Comércio das Américas (Alca).

É nesse cenário que o empresariado brasileiro vai tomar consciência da necessidade de aprimorar sua organização e mobilização política. O papel da Confederação Nacional da Indústria (CNI), nesse processo, foi fundamental para orientar a direção e as pautas a serem defendidas pelo empresariado nacional. Nesse caso, a estrutura corporativista passa a assumir a condição de empreendedor político.

Essa representação de interesses é tratada, ainda, em trabalhos sobre a atividade do lobby no Brasil (Aragão, 1994; Mancuso, 2007; Oliveira, 2004). Em sua forma lícita, o lobby torna-se um instrumento positivo para o processo democrático, sendo capaz de servir como "canal de comunicação entre os interesses organizados e o poder público" (Mancuso e Gozetto, 2011, p. 123). Todavia, o desequilíbrio de ordem financeira entre os diferentes segmentos sociais interfere diretamente na condução dessa atividade quando passa a servir para o favorecimento de interesses específicos.

\section{A zona portuária carioca em disputa}

A expansão territorial e populacional aliada ao deslocamento de atividades econômicas e funções administrativas para outros bairros fizeram a região portuária perder relevância na dinâmica econômica e social da cidade. Diferentemente da Área Central de Negócios ${ }^{2}$ (ACN), o deslocamento da capital federal para Brasília, em 1960, contribuiu para uma mudança no perfil dos bairros portuários Saúde, Gamboa e Santo Cristo.

O esvaziamento de prédios, antes utilizados pelo Governo Federal, e a ocupação residencial de baixa renda contribuíram para o processo de invisibilização da região em relação ao restante da cidade. Diante da percepção compartilhada socialmente de "vazio" na zona portuária abriu-se caminho para a atuação de grandes empresas de construção civil do país, o que estimulou a especulação imobiliária naquela área.

O sucesso dos projetos de revitalização em cidades portuárias europeias e norte-americanas, na segunda metade do século $X X$, como Manhattan (EUA) e Oslo (NOR), foi determinante para a emergência de novas propostas de intervenção para a região do porto no Rio de Janeiro. Em comum, tais iniciativas procuraram investir no estabelecimento de novas funções e na recuperação do valor do solo. Com a recuperação dessas áreas "degradadas", pretendia-se modernizar e modificar sua vocação econômica (Compans, 1998, p. 91).

No Rio de Janeiro, a crise econômica pela qual passou o País na década de 1980 trouxe, como consequência, uma atuação 
mais propositiva do empresariado em relação ao modelo de desenvolvimento a ser implementado no estado. Nesse momento, formou-se, com dirigentes, intelectuais e técnicos, o Instituto de Estudos Estratégicos do Rio de Janeiro, popularmente conhecido como Clube do Rio.

Em artigo publicado na edição do Jornal do Brasil, de 14 de dezembro de 1980, intitulado "Empresários planejam Clube do Rio para evitar esvaziamento", fica claro o intuito primordial do Clube do Rio, que se identificava como apolítico, embora disponível ao diálogo com todas as tendências, e aberto a participantes de quaisquer áreas além do empresariado:

O Estado do Rio se ressente de um lobby forte e atuante, de uma doutrina de desenvolvimento, de uma situação conjunta de suas lideranças mais ilustres e, sobretudo, de uma conscientização dos seus habitantes quanto à urgência do seu fortalecimento: "Estamos fazendo uma conspiração", sintetiza o empresário Mauro Magalhães, presidente da Ademi e um dos idealizadores do movimento, "no sentido de criar essa doutrina e de alastrar um novo sentimento".

O Clube do Rio era apresentado por seus membros como uma atuação estratégica conjunta que tinha o propósito de acabar com o quadro de esvaziamento político e econômico do estado. Entre os principais nomes por trás dessa iniciativa estão: Israel Klabin, sócio-gerente de Klabin Irmãos \& Cia. e ex-prefeito do Rio de Janeiro; Ruy Barreto, presidente da Associação Comercial do Rio de Janeiro (ACRJ); Arthur João Donato, presidente da Federação de Indústrias do Rio de Janeiro (Firjan); Mauro Magalhães, presidente da Associação de
Dirigentes do Mercado Imobiliário do Rio de Janeiro (Ademi/RJ); e Teophilo de Azeredo Santos, presidente da Federação Nacional dos Bancos e presidente do Banco Interpart.

Inicialmente, considerou-se a revisão de ideias apresentadas em anos anteriores, como a criação de um Centro Financeiro Internacional, no modelo defendido por Klabin quando ainda era prefeito e de um Centro Internacional do Comércio, transformando a capital em uma espécie de showroom; e o desenvolvimento do esboço do Projeto Cultural Rio. Entre outras ações do Clube do Rio, destaca-se a criação da empresa privada Riopart - Participações e Empreendimentos S.A. em 1982.

Constituída por 100 cotistas, a Riopart pretendeu reunir capitais privados para atuar como um instrumento de apoio ao desenvolvimento comercial, industrial e no setor de serviços do estado. 0 envolvimento maciço dos empresários que integravam tanto o Clube do Rio quanto os quadros principais da Associação Comercial do Rio de Janeiro (ACRJ) na gestão da Riopart ${ }^{3}$ indicou o protagonismo do setor nas intervenções urbanísticas projetadas para a zona portuária da cidade:

Ela [Riopart], na realidade, poderia ser considerada um braço da Associação Comercial uma vez que todos os seus cotistas participam também desta, possuem objetivos complementares e seus diretores-presidentes vêm intercambiando-se desde sua criação. Assim, não pode haver conflito de interesse entre as duas. (Del Rio, 1991, p. 292)

Em outubro do mesmo ano, a ACRJ e a Riopart promoveram a I Semana Rio Internacional. Com apoio do Instituto dos Arquitetos do Brasil (IAB-RJ), buscaram discutir as 
potencialidades da cidade e as possibilidades de incremento do comércio exportador na cidade. Em meio às muitas conclusões extraídas do evento, a região portuária é mencionada por seus inúmeros atrativos. São eles: edificações e áreas subutilizadas; fácil acessibilidade e proximidade do centro; potencial turístico e histórico; e conjugação com o porto, que deveria receber investimento em melhorias de sua operacionalidade. Tais mudanças, segundo a ACRJ, iriam afirmar a vocação internacional da cidade e reestabelecer o crescimento econômico do País. ${ }^{4}$

Observa-se que setores do empresariado carioca, representados pela ACRJ e a Riopart, buscaram propor novos usos ao porto da cidade. Com a finalidade de ratificar suas ideias de reabilitação da zona portuária, a Riopart realizou um Cadastro Físico da Área Portuária do Rio de Janeiro. No levantamento foram indicados terrenos e armazéns ociosos que somavam pouco mais de $77 \mathrm{mil} \mathrm{m}^{2}$, incluindo uma antiga oficina, um prédio de serviço e seu terreno, também pertencentes à Companhia Docas do Rio de Janeiro ${ }^{5}$ (Del Rio, 1991, pp. 294-295). 0 projeto, apresentado e debatido na I Semana Rio Internacional, delimitou seu recorte geográfico a partir da Praça XV, seguindo pelo cais e terminando nas Avenidas Francisco Bicalho e Getúlio Vargas. Com isso, incluiu os bairros da Saúde, Gamboa, Santo Cristo e Caju.

Outras quatro edições da Semana Rio Internacional aconteceram entre os anos de 1982 a 1985. Nestes encontros estabeleceram um espaço estratégico de articulação e concretização de ideias, como o Centro Internacional do Comércio, capaz de promover a renovação da zona portuária carioca, tendo como objetivo principal gerar as condições necessárias para a implementação do CIC.
Para isso, contaram com a presença de figuras importantes no cenário comercial e econômico internacional, como o secretário-geral da World Trade Centers Association, Thomas Kearney, e os membros representantes de Cingapura, Londres e Nova York. A exposição feita por representantes de outros países se alinhava ao pensamento do empresariado local, como é possível notar na passagem do artigo publicado na Revista do Empresário da ACRJ:

Um centro de comércio internacional, na sua opinião [Thomas Kearney], é mais do que um prédio especializado, é um ponto de encontro entre compradores e vendedores em um local onde, além de escritórios, encontra-se também, hotéis, restaurantes, locais para exposição, centros de pesquisa, auditório e, fora do movimento de negócios, se realizam ainda seminários sobre gerenciamento internacional e treinamento para a comunidade. Na realidade, o $\mathrm{CCl}$ seria uma extensão de um fenômeno praticamente natural, já que todas as cidades têm uma praça principal de comércio. Um CCl - diz ele - nada mais é do que um passo à frente, com a criação de um shopping center altamente especializado, num lugar os elementos envolvidos podem se concentrar e interagir mais facilmente, visando a realização do comércio conjuntamente. (Associação Comercial do Rio de Janeiro, 1983, pp. 7-8)

Além de outros nomes importantes do empresariado nacional e internacional, como o empresário Ruy Barreto e o ex-diretor da Hudson Institute dos Estados Unidos, Robert Panero, os eventos contaram também com a presença de representantes do poder público. 
Ainda em 1983, o arquiteto Jayme Lerner e Pedro Batouli, então presidente da Companhia Docas, levaram suas contribuições sobre a política urbana do Rio de Janeiro e a implementação do World Trade Center na cidade.

Jayme Lerner ressaltou as dificuldades existentes na execução desses empreendimentos, que deveriam respeitar o comércio e os aspectos humanos da urbe ao invés de tentar substituí-la ou modificá-la. Em sua visão, "a cidade é, antes de mais nada, um ponto de encontro de pessoas e precisa da integração das diversas funções" (Associação Comercial do Rio de Janeiro, 1983, p. 17).

Em contrapartida, Pedro Batouli lembrou das especificidades do caso brasileiro que delimitam um caminho de organização, tornando distinto daqueles apresentados pelas entidades estrangeiras. Sem discordar da necessidade do projeto, o presidente da Companhia Docas acrescentou a urgência em dispor de um novo layout para o porto, estabelecido após a realização de um concurso nacional, promovido pela ACRJ e patrocinado pela Riopart, para a urbanização da região (ibid., p. 11).

Dificuldades na burocracia e, principalmente, as divergências com essas representações inviabilizaram a efetivação da parceria para a proposta de utilização das instalações portuárias por parte da ACRJ. A Companhia Docas, por exemplo, opôs-se à demanda pela cessão de armazéns e outros terrenos de sua posse para a implementação do projeto. No seu ponto de vista, a função portuária e suas instalações deveriam permanecer sob seu controle.

Já a prefeitura, que tem poder discricionário em legislar e controlar o uso e a ocupação do solo urbano, não se mostrou alinhada à proposta em questão. Assim como os moradores da região, entidades profissionais e órgãos da administração pública mostraram-se resistentes ao projeto.

Em oposição ao projeto, foi criado o Projeto Sagas, que propôs uma nova legislação sobre uso residencial e preservação do patrimônio arquitetônico e ambiental para a área. Em consonância às diretrizes e medidas já consolidadas nos órgãos de planejamento municipal e de preservação do patrimônio da época, como Superintendência de Planejamento Urbano da Secretaria Municipal de Planejamento ${ }^{6}$ e Secretaria de Patrimônio Histórico e Artístico Nacional (Sphan), o projeto buscou incentivar a recuperação de edificações típicas do local, identificadas por meio de inventários e pesquisa histórica (Sampaio, 1994).

Inspirado em outra iniciativa municipal, o Projeto Corredor Cultural, ${ }^{7}$ o Sagas pretendeu criar instrumentos que contribuíssem com a preservação ambiental e do patrimônio arquitetônico local, em parceria com moradores da região. Segundo Rose Compans, entretanto, tais projetos apresentavam diferenças substanciais:

\begin{abstract}
Embora concebido nos mesmos moldes do Projeto Corredor Cultural, o Projeto Sagas se concentrou mais na definição de parâmetros para a ocupação - por meio da elaboração de legislação do uso do solo - do que da conservação do ambiente construído. Isso porque, diferentemente do primeiro, compreendia uma área em que havia muitos terrenos vazios e prédios sem valor histórico. (Compans, 2004, p. 52)
\end{abstract}

Com a instituição da lei n. 971, de 1987, ficou delimitada a área de proteção do ambiente cultural na região que engloba os bairros da Saúde, Gamboa e Santo Cristo, a Apac - Sagas. 
No momento em que a região passa a ter status patrimonial, a implementação do Centro Internacional de Comércio, planejada pela Riopart e ACRJ, torna-se inviável.

Percebe-se, nessa ocasião, que as ações municipais passavam a sofrer influência dos temas e proposições que ganhariam a pauta urbana na Constituição de 1988. A democratização do espaço urbano e a preservação ambiental interferiam na elaboração de políticas que valorizassem as atividades locais e que preservassem o patrimônio arquitetônico, cultural e natural da região portuária.

Por conta desse cenário, ainda no final da década de 1980 , foi elaborado um projeto alternativo de desenvolvimento portuário na área de propriedade da Companhia Docas, encomendado, pela Portobras e Ministério dos Transportes, à Planave, empresa de engenharia de infraestrutura com ênfase no setor portuário e energético (Del Rio, 1991). Contudo, acabou sendo abandonado para dar lugar a uma proposta destinada à área não utilizável do porto com o intuito de integrá-la ao restante da região (Moreira, 2004).

Sob o comando de César Maia, a prefeitura mostrou-se mais disponível ao diálogo com a ACRJ, que retomou os esforços de emplacar um projeto de reestruturação da região portuária. Em 1993, a primeira edição da $R e$ vista do Empresário da ACRJ colocou como matéria de capa o projeto de revitalização a ser posto em prática pelo recém-eleito César Maia e destacou a capacidade do prefeito para executá-lo:

Profundo conhecedor dos problemas da cidade, César Maia prometeu recuperar o Rio econômico e socialmente. Para isso, ele se colocou acima das divergências políticas partidárias e já na campanha tentou se assessorar dos melhores quadros técnicos. Eleito, intensificou ainda mais essa relação, mostrando ao eleitor que acima de qualquer questão está a vontade de recuperar o Rio. (Associação Comercial do Rio de Janeiro, 1993, p. 17)

Logo após assumir, César Maia rejeitou os três projetos formulados pelo governo anterior e elaborou uma quarta proposta com o apoio do convênio estabelecido com a ACRJ e a Federação das Indústrias do Estado do Rio de Janeiro (Firjan). Luiz Paulo Conde, então Secretário Municipal de Urbanismo, trouxe, ainda, a consultoria da empresa catalã Tecnologias Urbanas de Barcelona (Tubsa) para auxiliar na formulação do Plano Estratégico da cidade. Sob o título "Rio sempre Rio", o Plano Estratégico do primeiro governo de César Maia mostrou-se como um instrumento, respaldado pela administração municipal, de consolidação dos interesses do empresariado carioca.

Entretanto, as discordâncias eram grandes em relação ao estipulado pelo grupo de trabalho criado da Secretaria Municipal de Urbanismo e Meio Ambiente, ainda na gestão Marcello Alencar. A criação de uma Câmara Técnica composta por especialistas, representantes de associação de moradores, empresários e representantes da Companhia Docas estimulava a concepção de projetos que atendessem aos interesses de todos. Além disso, as divergências com a Companhia Docas, que, por meio da lei federal n. 8.630/1993 ou Lei de Modernização dos Portos, passou a ter direito de estabelecer contratos de arrendamento para a exploração de instalações portuárias e a competência para aprovar planos de desenvolvimento e zoneamento do porto. ${ }^{8}$ 
Em meio a disputas e consensos que caracterizaram o debate em torno das propostas de intervenção para região, na década de 1990, é possível notar, entretanto, a construção de uma nova ideia de promoção para a zona portuária. Ao longo das administrações de César Maia e de Luiz Paulo Conde, instituiu-se um modelo municipal de gestão urbana compartilhado e desenvolvido até 1998, quando deixam de ser aliados políticos. ${ }^{9}$

Em 2001, novamente com César Maia no comando da prefeitura do Rio de Janeiro, definiu-se, como prioridade para a Secretaria de Urbanismo, o projeto "Porto do Rio - Plano de Recuperação e Revitalização da Região Portuária do Rio de Janeiro". Com Alfredo Sirkis na Secretaria Municipal de Urbanismo e na presidência do Instituto Pereira Passos (IPP), ${ }^{10}$ Maia pôde contar com um entusiasta da revitalização portuária carioca. Entretanto, diversos obstáculos legais e políticos, como o difícil diálogo com a Companhia Docas, também impediram que esse último plano fosse efetivado.

Outros projetos, como a construção do Museu Guggenheim, também apresentaram forte oposição de associação de moradores, entidades, além de antropólogos, artistas, arquitetos, historiadores, museólogos e urbanistas. Orçado em US\$133,6 milhões, em princípio, as despesas seriam arcadas pela prefeitura, apesar da autonomia de 25 anos concedida à Fundação Guggenheim para decidir sobre o acervo e programação da filial no Rio de Janeiro. Além disso, os lucros do museu seriam direcionados à Fundação com a finalidade de auxiliar na sua gestão.

A pressão da opinião pública não inibiu César Maia de assinar o contrato que permitia a construção do Museu junto à Fundação em 2003. Segundo o prefeito, a iniciativa justificava-se pelo impacto econômico trazido pelo projeto, que tornaria possível a revitalização da zona portuária.

A suspensão do contrato, por meio de ação popular, levou ao cancelamento das demais obras na região. De acordo com Maia, tornava-se inviável revitalizar a área sem um projeto-âncora.

Outros projetos foram criados com o intuito de revitalizar a região de modo distinto aquele apresentado para a construção do Museu Guggenheim, porém seguiram sem o êxito esperado. Nesse momento, parcerias com o Banco Nacional de Desenvolvimento Econômico e Social (BNDES) e Caixa Econômica Federal (CEF) indicavam uma aproximação com o governo federal e a intenção em transformar um projeto de intervenção na região em um modelo de gestão nacional.

Nesse processo, merece destaque a mudança na política de desenvolvimento nacional adotada pelo governo federal em razão da gestão Luiz Inácio Lula da Silva, iniciada em 2003. A criação do Ministério das Cidades, acompanhada do Programa de Reabilitação de Áreas Urbanas Centrais, colocou o tema da revitalização urbana na agenda prioritária do governo.

Baseado na Constituição de 1988 e no Estatuto da Cidade, de 2001, o Programa tinha como objetivo ampliar o acesso à terra bem localizada e com boa infraestrutura para a população de baixa renda. Para isso, previu a atuação integrada entre os entes federados, ministérios, empresários e órgãos federais detentores do patrimônio imobiliário localizado nas áreas centrais.

A Caixa Econômica Federal é o agente operador de parte dos recursos orçamentários do Programa e do Ministério das Cidades. 
Participa ainda da cooperação estabelecida com o governo francês para a definição de Perímetros de Intervenção Integrados.

O Ministério da Cultura atua na elaboração de planos de preservação de sítios históricos por meio do Programa Monumenta e pelo Instituto Histórico e Artístico Nacional (Iphan). Por meio do Programa Nacional de Desenvolvimento do Turismo (Prodetur), o Ministério do Turismo passa a investir em atividades de intensificação do potencial turístico, enquanto o Ministério dos Transportes cuidava da infraestrutura rodoviária, ferroviária e portuária. Já o Ministério do Planejamento torna-se responsável pela gestão das áreas pertencentes à União e pelo acompanhamento dos processos de liquidação de empresas federais, como a Rede Ferroviária Federal.

No caso da revitalização portuária carioca, ressaltou-se a necessidade em estipular um projeto que abarcasse todas as propostas pontuais apresentadas pela prefeitura do Rio de Janeiro. Tendo o objetivo de auxiliar uma reorientação estratégica municipal e acompanhar a implementação das ações de intervenção na região, for criado um Grupo de Trabalho Interministerial. Sob coordenação do Ministério do Planejamento, o Grupo de Trabalho era integrado por Casa Civil da Presidência da República, Ministério das Cidades, Ministério da Justiça, Companhia Docas do Rio de Janeiro, Companhia Nacional de Abastecimento (Conab), CEF e BNDES. Participaram ainda, como convidados, a Rede Ferroviária Federal, o Ministério da Cultura, o Instituto Nacional de Seguridade Social (INSS), o Instituto Brasileiro de Geografia e Estatística (IBGE), o Instituto dos Advogados do Brasil, a ACRJ e a Firjan (Ministério das Cidades, 2005, pp. 30-31). Estimulados pela instituição da lei federal n. 11.107/2005, que dispõe sobre os consórcios públicos, a operação urbana consorciada passa a ser compreendida como a opção mais viável para o caso.

No âmbito regional, destaca-se o papel do governador Sérgio Cabral Filho na costura de alianças políticas e empresariais necessárias para alavancar a candidatura municipal de Eduardo Paes. Com isso, ficaria garantida a ausência de divergências claras entre os poderes federal, estadual e municipal.

Embora tenha participado do governo de Cesar Maia, Eduardo Paes consolidou-se como uma figura influente no cenário político carioca a partir de seu trabalho como Secretário Estadual de Turismo, Esporte e Lazer de Cabral. Durante sua atuação na secretaria, envolveu-se na fase final de preparação dos Jogos Pan-Americanos de 2007 e nas candidaturas da cidade para sediar a Copa do Mundo de 2014 e os Jogos Olímpicos de 2016.

Quando saiu do PSDB para se filiar ao PMDB, Eduardo Paes colocou-se como um candidato a prefeito alinhado aos interesses dos executivos federal ${ }^{11}$ e estadual. Ao mesmo tempo, a vitória de Paes representaria uma postura mais pragmática com a iniciativa privada, tendo como objetivo a execução de um novo ciclo de investimentos necessários para a preparação da cidade aos megaeventos.

Ainda em julho de 2008, Olavo Monteiro de Carvalho, presidente da ACRJ, já sinalizava a importância de um prefeito que atuasse de modo convergente aos propósitos que se delineavam para a região:

O potencial de crescimento econômico do estado, com investimentos públicos e privados em torno de $\mathrm{R} \$ 100$ bilhões, até 2010 , descortina um cenário de inúmeras oportunidades, em especial, para a cidade do Rio de Janeiro, que realizará 
jogos da Copa do Mundo, em 2014, e é candidata a sediar as Olimpíadas de 2016, o maior evento esportivo do planeta. Com essa perspectiva, a revitalização do Porto do Rio - incluindo a renovação dos bairros da zona portuária - torna-se imperativa. [...] Para que isso aconteça, será fundamental o diálogo efetivo do futuro prefeito com os governos estadual e federal e o setor privado. Alianças facilitam decisões, acordos e o rápido acesso a inovações e tecnologias. É hora de resgatar a importância econômica e histórica do porto e seu entorno, promovendo uma nova "abertura às nações amigas". (Jornal O Globo, 2008, p. 4)

Após tomar posse, uma das primeiras medidas adotadas por Paes foi a elaboração de um Plano Diretor que reformulasse as normas e os procedimentos para a política de ocupação urbana. A criação de incentivos para a ocupação de galpões e prédios abandonados ou considerados "vazios urbanos", a regulamentação de novas regras para a participação da iniciativa privada na prestação de serviços públicos, por meio de parcerias público-privadas, e a execução da operação urbana consorciada na zona portuária fundamentariam o documento.

\section{Porto Maravilha: operação urbana consorciada na zona portuária do Rio de Janeiro}

De acordo com o $\S 1$ 엉 do art. 32 do Estatuto da Cidade, é considerado uma Operação Urbana Consorciada o conjunto de intervenções coordenadas pelos municípios "com a participação dos proprietários, moradores, usuários permanentes e investidores privados, com o objetivo de alcançar em uma área transformações urbanísticas estruturais, melhorias sociais e a valorização ambiental". Por meio de uma lei municipal específica, apoiada no plano diretor, ficam estabelecidos: definição da área a ser atingida; programa básico de ocupação da área; programa de atendimento econômico e social para a população diretamente afetada pela operação; finalidades da operação; estudo prévio de impacto de vizinhança; contrapartida, a ser exigida dos proprietários, usuários permanentes e investidores privados; e forma de controle de operação, obrigatoriamente compartilhado com representação da sociedade civil.

A lei municipal específica que aprovar a Operação Urbana Consorciada poderá ainda prever a emissão pelo município de uma quantidade determinada de Certificados de Potencial Adicional de Construção (Cepacs) que serão alienados em leilão na forma da Lei de Licitações e Contratos Administrativos (lei n. 8.666/1993) ou utilizados diretamente no pagamento das obras necessárias à própria operação. Os Cepacs serão livremente negociados, mas conversíveis em direito de construir unicamente na área objeto da operação.

No Rio de Janeiro, como apresentado na seção anterior, foram elaboradas inúmeras propostas de proteção e revitalização que priorizaram a região portuária da cidade. $\mathrm{E}$, apesar das diversas tentativas, foi com o Projeto Porto Maravilha que a localidade passou a receber maior notoriedade entre atores políticos, empresariado e sociedade civil.

Criada pela lei n. 101/2009, a Operação Urbana Consorciada da Área de Especial Interesse Urbanístico da Região Portuária do Rio de Janeiro, também conhecida como Porto Maravilha, estabeleceu como objetivo 
principal promover a estruturação urbana "por meio da ampliação, articulação e requalificação dos espaços livres de uso público da região do Porto, visando à melhoria da qualidade de vida de seus atuais e futuros moradores e à sustentabilidade ambiental e socioeconômica da região". A Companhia de Desenvolvimento Urbano da Região do Porto (Cdurp) ficou responsável pelo gerenciamento das obras enquanto a Concessionária Porto Novo, por meio de parceria público-privada com a prefeitura, pela execução das obras e prestação de serviços urbanos, como pavimentação de ruas e recomposição de viadutos.

O Projeto Porto Maravilha circunscreve a região portuária do Rio de Janeiro, de cerca de cinco milhões de metros quadrados, que inclui os bairros da Saúde, Gamboa, Santo Cristo e parte dos bairros do Caju, São Cristóvão e Centro. Além da escolha do Rio de Janeiro como uma das sedes da Copa do Mundo em 2014 e sede oficial das Olimpíadas de 2016, percebeu-se a valorização da relevância histórica da região portuária para a concepção do projeto. Por esse motivo, ficou estabelecido o direcionamento de, pelo menos, $3 \%$ dos recursos da venda dos Cepacs à valorização do Patrimônio Material e Imaterial da área em programas de desenvolvimento social para moradores e trabalhadores.

Tratando-se de um instrumento urbanístico que prevê intervenções e medidas na região coordenadas pelo poder municipal com a participação de proprietários, moradores, usuários permanentes e investidores privados, o estabelecimento de uma gestão democrática e inclusiva seria fundamental. Entretanto, ao contrário do previsto no Estatuto da Cidade, a Operação Urbana Consorciada é duramente criticada pela pouca participação de atores sociais e frequentemente relacionada aos processos de especularização imobiliária e gentrificação na região.

\section{Empreendedorismo urbano como um modelo de gestão pública}

Tais considerações contribuem para a reflexão dos processos recentes de reestruturação urbana visto que a incorporação de ações governamentais "empreendedoras" (Harvey, 2005) interfere diretamente na consolidação de novas distribuições geográficas da atividade humana e dinâmicas político-econômicas. As cidades passam a direcionar seus investimentos em infraestrutura e na criação de novas atrações de consumo e/ou entretenimento em áreas até então pouco assistidas pelo poder público.

A disputa entre cidades para atrair benefícios e capitais desponta como aspecto a contribuir na orientação das políticas públicas para uma perspectiva competitiva, das quais "pode ser destacado, pela capacidade de canalizar forças sociais e de propiciar um momento de produção da imagem que a cidade tem de si, o planejamento estratégico da cidade" (Lima Júnior, 2010, p. 1). Nesse momento, competitividade e produtividade tornam-se termos centrais na problemática urbana das cidades contemporâneas.

Na prática, o processo decisório manteve-se na competência dos agentes públicos e setores que já possuíam influência política. A parceria público-privada surge, nesse momento, como instrumento para assegurar a presença dos interesses do mercado no processo de planejamento e de decisão. Ao adotarem 
características próximas àquelas encontradas nas lideranças empresariais, cria-se um novo perfil de governabilidade.

É possível dizer que as municipalidades seguem na liderança das ações de elaboração e implementação das políticas urbanas adotadas, sendo fundamentais no processo de atração de investimentos privados. Entretanto, ao usarem novas estratégias de recapitalização, com maior participação da iniciativa privada, passam a explorar, no comportamento empresarial, mecanismos a serem incorporados para fins especulativos.

Consequentemente, a participação e a representação dos cidadãos na formulação de uma agenda urbana ficam limitadas a interesses específicos de setores políticos e econômicos influentes. É, nesse contexto, que se insere a aplicação da Operação Urbana Consorciada na cidade do Rio de Janeiro.

\section{Considerações finais}

Tendo a literatura que trata da construção da agenda governamental como marco analítico, especialmente a atuação de grupos de interesses, procurou-se avaliar a influência política do empresariado urbano na aplicação da Operação Urbana Consorciada na cidade do Rio de Janeiro. Ao utilizar documentos oficiais, jornais, revistas e observação direta, pretendeu-se observar, de modo complementar, o papel desses atores na estruturação de um modelo de gestão a ser implantado para a região portuária.

Ao discorrer sobre a influência de agentes econômicos na aprovação e na elaboração da agenda urbana, identificou-se a perpetuação de determinados atores e práticas de governabilidade. A constante presença da
Associação Comercial do Rio de Janeiro nas propostas de revitalização para a zona portuária exemplifica tal situação. Entre consensos e discordâncias com o poder municipal e a Companhia Docas, a entidade tornou-se fundamental na definição e na condução de um modelo de gestão portuária para a cidade.

Entretanto, somente nos anos 2000, a revitalização de áreas urbanas centrais ganhou protagonismo no programa de desenvolvimento federal. A criação do Ministério da Cidades e do Programa de Reabilitação de Áreas Urbanas Centrais conferiu o suporte necessário para a execução de um projeto para a região portuária do Rio de Janeiro.

O financiamento da Operação Urbana Consorciada reflete o esforço em atender aos interesses da União, estado, município e empresariado. Diante da dificuldade em alcançar orçamento suficiente para arcar com projetos de grande porte, foram criadas as Cepacs. Sua excepcionalidade reside em não constituir dívida ao município que o lança enquanto se torna um importante meio de assunção de responsabilidades e capacidades. No entanto, esse modelo de financiamento municipal costuma ser criticado pela grande probabilidade de promover ou ampliar ainda mais a concentração de recursos públicos e privados.

Ao analisar o caso do Rio de Janeiro, é possível notar que a introdução de instrumentos democráticos, como a ampliação dos canais de participação política e a instituição do Estatuto da Cidade, não foi suficiente para reduzir as assimetrias na gestão urbana. Pode-se dizer que a continuidade de uma rede de relações composta por atores hegemônicos orientou o processo de configuração de novos arranjos institucionais e de novas formas organizacionais para a região portuária carioca. 


\section{[I] https://orcid.org/0000-0002-0840-0856}

Universidade Federal Fluminense, Instituto de Ciências Humanas e Filosofia, Programa de Pós-Graduação em Ciência Política. Niterói, RJ/Brasil.

julia_riscado@yahoo.com.br

\section{Notas}

(1) Entre os anos de 1949 a 1953, o Ministério da Fazenda foi ocupado por Guilherme da Silveira, ligado à Federação das Indústrias do Estado do Rio de Janeiro (Firjan), e Horácio Lafer, ligado à Fiesp. Como pontuou Barbosa (2013), tal fato ajuda a explicar a proteção da indústria pela política cambial do governo no período.

(2) O trecho que engloba a Área Central de Negócios ( $A C N$ ) corresponde aos bairros do Centro, que contém a área de negócios, Lapa, Bairro de Fátima e Cruz Vermelha. Nesse anel periférico, concentram-se funções de centro comercial, administrativo, bancário-financeiro, artístico-cultural e de informações, e o seu entorno imediato, onde se encontram áreas de pequeno comércio e residenciais.

(3) O primeiro presidente da Riopart foi Amaury Temporal, vice-presidente da ACRJ, e o primeiro presidente do Conselho Administrativo da Riopart foi Paulo Manoel Protássio, diretor da ACRJ.

(4) As ideias principais do projeto foram amplamente divulgadas nos meios de comunicação, como, por exemplo, em artigos publicados no Jornal O Globo nas edições de 3 de fevereiro de 1983 e de 4 de setembro de 1983. Disponível em: <https://acervo.oglobo.globo.com/>, acesso em: 10 set 2019 .

(5) Com a extinção da Autarquia Federal denominada Administração do Porto do Rio de Janeiro, foi instituída, pelo decreto-lei n. 256/1966, a Companhia Docas do Rio de Janeiro (CDRJ). A criação da sociedade de economia mista tem por objeto a administração do porto do Rio de Janeiro e demais portos localizados no Estado. Disponível em: <https://www.planalto.gov.br/ccivil_03/ decreto-lei/1965-1988/del0256.htm>, acesso em: 11 set 2019.

(6) Criado em 1984 como órgão de assessoramento do Conselho Municipal de Proteção do Patrimônio Cultural (CMPPC) foi transformado, em 1986, no Departamento Geral de Patrimônio Cultural (DGPC).

(7) O Projeto Corredor Cultural, de 1984, foi o primeiro projeto de preservação para a área central da cidade que abrangeu as áreas da Lapa, Cinelândia, Largo da Carioca, Largo do São Francisco e Saara. O projeto foi idealizado com o objetivo de promover ações de proteção e revitalização em parceria com moradores e usuários da região do Centro do Rio de Janeiro. No artigo "A reabilitação urbana em processo", escrito vinte anos após a criação do Corredor Cultural, um de seus idealizadores, o arquiteto Augusto Ivan Pinheiro, destacou as quatro etapas em que foi dividido o projeto: de implementação, com a delimitação do quadro legal e institucional; de consolidação, com a materialização, aprofundamento, recuperação e conservação; de estruturação, com a incorporação dos aspectos públicos e das melhorias; de integração, com a adesão de outros atores e outros processos (Pinheiro, 2004, p. 72). 
(8) Nesse mesmo ano, o Ministério dos Transportes lançou o Programa Nacional de Revitalização de Áreas Portuárias (Revap) e levou a Companhia Docas a se envolver mais no Projeto de Desenvolvimento e Privatização Aplicado ao Complexo Portuário do Rio de Janeiro (Compans, 2004, p. 55).

(9) César Maia foi prefeito do Rio de Janeiro entre 1993-1997, sendo sucedido por Luiz Paulo Conde (1997-2001), e retornou em mais dois mandatos, 2001-2005 e 2005-2009. “Deve-se registrar que, até os primeiros anos de sua administração, Conde ainda era aliado político de César Maia. Ao longo do mandato de Conde, principalmente após a derrota eleitoral de César Maia em 1998 quando se lançou-se candidato ao governo do estado, os dois passaram de aliados a ferrenhos adversários. César Maia mudou de partido, para disputar as eleições para prefeito do Rio de Janeiro em 2000, quando saiu vitorioso, rivalizando com Conde no segundo turno" (Barandier, 2003, pp. 51-52).

(10) O IPP assumiu as atividades de planejamento urbano, produção cartográfica e de estatísticas do município do Rio de Janeiro após o desmembramento do Iplanrio, em 1999.

(11) Cabe destacar, entretanto, que o apoio oficial do presidente ocorreu somente no segundo turno das eleições municipais. Durante a campanha eleitoral, Eduardo Paes chegou a enviar uma carta se desculpando pelas críticas dirigidas ao então Presidente da República. Fonte: https://www1. folha.uol.com.br/poder/2008/10/461773-paes-se-encontra-com-lula-e-diz-que-governosmunicipal-e-federal-vao-trabalhar-juntos.shtml, acesso em: 4 abr 2020.

\section{Referências}

ACRJ - Associação Comercial do Rio de Janeiro (1983). Revista do Empresário. Rio de Janeiro, Ano 43, n. 1192.

(1993). Revista do Empresário. Rio de Janeiro, Ano 54, n. 1278.

ARAGÃO, M. (1994). Grupos de pressão no Congresso Nacional: como a sociedade pode defender licitamente seus direitos no poder legislativo. São Paulo, Maltese.

BARANDIER, H. G. (2003). Projetos urbanos na área central do Rio de Janeiro (1993-2000). Dissertação de mestrado. Rio de Janeiro, Universidade Federal do Rio de Janeiro.

BARBOSA, A. S. (2013). Revisitando a literatura do empresariado industrial brasileiro: dilemas e controvérsias. Caderno CRH. Salvador, v. 26, n. 68, pp. 391-406.

BOSCHI, R. R. (1979). Elites industriais e democracia: hegemonia burguesa e mudança política no Brasil. Rio de Janeiro, Graal.

BRESSER-PEREIRA, L. C. (2002). “Empresários, suas origens e as interpretações no Brasil”. In: SZMRECSÁNYI, T. e MARANHÃO, R. (orgs.). História de Empresas e Desenvolvimento Econômico. São Paulo, Hucitec/ABPHE/Edusp.

CANO, W. (1998). Raízes da concentração industrial em São Paulo. São Paulo, Unicamp/IE. 
CHRISTOPOULOS, D. C. (2006). Relational attributes of political entrepreneurs: a network perspective. Journal of European Public Policy, v. 13, n. 5, pp. 757-778.

COMPANS, R. (1998). Parceria público-privado na gestão do espaço urbano: o caso da renovação da zona portuária do Rio de Janeiro. Cadernos Ippur. Rio de Janeiro, Ano XII, n. 1, pp. 90-105.

(2004). "Intervenções de recuperação de zonas urbanas centrais: experiências nacionais e internacionais". In: COMIN, A.; SOMEKH, N. (coords.). Caminhos para o centro: estratégias de desenvolvimento para a região central de São Paulo. São Paulo, Empresa Municipal de Urbanização; Prefeitura de São Paulo; Centro Brasileiro de Análise e Planejamento; Centro de Estudos da Metrópole, pp. 24-60.

DEAN, W. (1971). A industrialização de São Paulo. São Paulo, Difel/Edusp.

DEL RIO, V. (1991). Desenho urbano e revitalização na área portuária do Rio de Janeiro: a contribuição do estudo da percepção ambiental. Tese de doutorado. São Paulo, Universidade de São Paulo.

DINIZ, E. (1978). Empresário, Estado e capitalismo no Brasil (1930-1945). Rio de Janeiro, Paz e Terra.

DINIZ, E.; BOSCHI, R. (1978). Empresariado Nacional e Estado no Brasil. Rio de Janeiro, Forense Universitária.

(2000). Globalização e elites empresariais: padrões alternativos de relações entre os setores público e privado no Brasil. In: XXIV ENCONTRO ANUAL DA ANPOCS. Anais... Petrópolis.

DREIFUSS, R. A. (1981). 1964: a conquista do Estado. Petrópolis, Vozes.

FERNANDES, F. (1987). A Revolução Burguesa no Brasil. Rio de Janeiro, Guanabara.

HARVEY, D. (2005). “Do administrativismo ao empreendedorismo: a formação da governança urbana no capitalismo tardio". In: HARVEY, D. A produção capitalista do espaço. São Paulo, Annablume.

IANNI, O. (1963). Industrialização e desenvolvimento industrial no Brasil. Rio de Janeiro, Civilização Brasileira.

JORNAL O GLOBO (2008). Em defesa do Porto. Caderno País, p. 4.

KINGDON, J. W. (2003). Agendas, alternatives and public policies. Ann Arbor, University of Michigan.

LEOPOLDI, M. A. P. (1984). Industrial Associations and Politics in Contemporary Brazil (1930-1961). Oxford, Universidade de Oxford.

(2000). Política e interesses na industrialização brasileira: as associações industriais, a política econômica e o Estado. Rio de Janeiro, Paz e Terra.

LIMA JÚNIOR, P. N. (2010). Uma estratégia chamada planejamento estratégico. Rio de Janeiro, 7 Letras.

MANCUSO, W. P. (2007). O lobby da indústria no Congresso Nacional: empresariado e política no Brasil contemporâneo. São Paulo, Edusp/Humanitas/Fapesp.

MANCUSO, W. P.; GOZETTO, A. C. O. (2011). Lobby: instrumento democrático de representação de interesses? Revista Organicom, v. 8, n. 14, pp. 119- 128.

MARTINS, J. S. (1986). Reforma agrária e os limites da democracia na Nova República. São Paulo, Hucitec. 
MINISTÉRIO DAS CIDADES (2005). Reabilitação de centros urbanos. Brasília.

MINTROM, M.; NORNAN, P. (2009). Policy Entrepreneurship and Policy Change. Policy Studies Journal, v. 37, n. 4 , pp. 649-667.

MOREIRA, C. C. (2004). A cidade contemporânea entre a tabula rasa e a preservação: cenários para o Porto do Rio. São Paulo, Editora Unesp.

OLIVEIRA, A. C. J. (2004). Lobby e representação de interesses: lobistas e seu impacto na representação de interesses no Brasil. Tese de doutorado. Campinas, Universidade Estadual de Campinas.

PAYNE, L. A. (1994). Brazilian industrialists and democratic change. Baltimore, The Johns Hopkins University.

PERISSINOTTO, R. M. (1991). Frações de classe e hegemonia na Primeira República em São Paulo. Dissertação de mestrado. Campinas, Universidade Estadual de Campinas.

PINHEIRO, A. I. de F. (2004). “A reabilitação urbana em processo”. In: LIMA, E. F. W.; MALEQUE, M. R. (orgs.). Cultura, patrimônio e habitação: possibilidades e modelos. Rio de Janeiro, 7 Letras.

SAMPAIO, J. C. R. (1994). A trajetória da preservação dos bairros da Saúde, Gamboa e Santo Cristo. Cadernos do Patrimônio Cultural. Rio de Janeiro, n. 4, pp. 68-78.

SILVA, S. (1976). Expansão cafeeira e origens da industrialização no Brasil. São Paulo, Alfa-Omega.

SODRÉ, N. W. (1967). História da burguesia brasileira. Rio de Janeiro, Civilização Brasileira.

TAVARES, M. C. (1972). Da substituição de importações ao capitalismo financeiro. Rio de Janeiro, Zahar.

VIANNA, O. (1987). História social da economia capitalista no Brasil. Belo Horizonte, Itatiaia/Rio de Janeiro, Eduff.

ZAHARIADIS, N. (2007). "The multiple streams framework: structure, limitations, prospects". In: SABATIER, P. A. (ed.). Theories of the policy process. Boulder, Westview.

Texto recebido em 4/jan/2019 Texto aprovado em 11/nov/2019 
